Hijai - Journal on Arabic Language and Literature | ISSN: 2621-1343

\title{
YERUSALEM DALAM PUISI AL-QUDS KARYA NIZAR QABBANI (Kajian Semiotika Charles Sanders Pierce)
}

\author{
Astri Aspianti Sahida dan Dedi Supriadi \\ UIN Sunan Gunung Djati Bandung \\ astriassahida@gmail.com, dedisupriadi@uinsgd.ac.id
}

\begin{abstract}
ABSTRAK
Konflik di Palestina-Israel menjadi perbincangan panjang dunia. Perang yang berlangsung sejak masa kekhalifahan itu terus terjadi hingga kini. Yerusalem atau Al-Quds biasa orang Arab menyebutnya sebagai kota yang indah, bukan hanya dari segi bangunannya namun juga memiliki kedudukan inti dari ketiga agama samawi, tiga simbol hidup damai dengan berdampingan. Tujuan penelitian ini untuk memaparkan deskripsi atau situasi kondisi Yerusalem dalam puisi Al-Quds serta mendeskripsikan makna dari simbol yang terdapat didalamnya. Metode yang digunakan ialah deskriptif analitik. Adapun teori pendekatan yang digunakan ialah teori pendekatan semiotika Charles Sanders Peirce untuk menjelaskan proses semiosis segitiga tanda atau yang kita kenal sebagai triadik untuk mengetahui Representament, Object, dan Interpretant, kemudian dihubungkan dengan sejarah yang melatarbelakanginya. Hasil penelitian dalam puisi Al-Quds karya Nizar Qabbani yang terdiri dari 39 bait tersebut dapat disimpulkan bahwa keadaan yang tergambar dalam puisi menunjukan kondisi Yerusalem atau Al-Quds yang sedang bersedih akibat perang yang berlangsung sejak lama. Pengarang dengan gaya bahasa yang selalu mengindikasikan sebuah ratapan, seakan menggambarkan bahwa tidak ada satupun hal yang dapat ia lakukan. Nizar Qabbani banyak menggunakan kata tanya dalam puisinya guna menjadi bahan muhasabah diri bahwa apa yang harusnya kita lalukan sebagai sesama manusia kepada para pembacanya. Dan tidak hanya itu, dalam puisi pun terekam dampak buruk terjadi yang diakibatkan oleh perang itu sendiri.
\end{abstract}

Kata kunci : Yerusalem, Al-Quds, Puisi, Semiotika, Charles Sanders Peirce, Sejarah.

\section{ABSTRACT}

Long conflicts of Israel-Palestine have been an animated topic of discussion everywhere in the world. This paper aims to unveil Jerusalem's description in poetry entitled Al-Quds by Nizar Qabbani and describe the symbols' meaning. The method used is descriptive analytics. The theoretical approach used is the semiotics theory by Charles Sanders Peirce, sign triangle or triadic to find out the Representament, Object, and Interpretant, and try to connect its history. The study reveals that poetry consists of 39 stanzas depicts the dreadful situation in Jerusalem due to constant conflicts there. His language 
style is a multitude of laments that illustrate nothing we can do in this hopeless, desperate predicament of endless war. He uses question words in his poetry for muhasabah (self-retrospections) he believes we should do as fellow human beings. The poetry also records all the war's harmful effects, where the hope for peace settlement as a final solution seems going amiss.

Keywords: Jerusalem, Al-Quds, Poetry, Semiotics, Charles Sanders Peirce, History.

\section{PENDAHULUAN}

Puisi merupakan bagian dari karya yang memiliki makna, makna tersebut dapat mewakili banyak hal, dapat mengenai judul puisi atau pengarangnya sendiri. Karena sebuah karya sastra tersebut dapat merupakan sebuah gambaran akan segala seguatu, bisa mengenai perasaan, gagasan, hingga keadaan yang tengah terjadi di suatu tempat.

Puisi sangat kaya akan simbol yang menjadi unsur pembentuknya. Simbol diciptakan manusia untuk berintaksi sehingga mencapai kesepahaman yang sama. Maka dari itu manusia kerap disebut sebagai makhluk simbolik. Sebagai contoh jika seseorang berkata "Aku tidak ingin kau pergi." Dapat bermakna larangan pergi yang sesungguhnya. Namun terkadang dapat bermakna lain jika disampaikan dengan "Mungkin aku tidak ingin kau pergi." Karena kata 'mungkin' dapat bermakna keraguan dan lainlain yang menyebabkan kesan yang justru sebaliknya. Selaras dengan ungkapan James P. Spradley bahwa simbol ialah sebuah objek ataupun sebuah peristiwa apapun yang merujuk kepada sesuatu (Sobur, 2006, p. 154).

Bahasa ialah medium dari karya sastra, yakni sistem semiotik atau ketandaan, dengan kata lain sistem ketandaan yang memiliki arti. Karya sastra tidak memiliki medium yang bebas (netral) layaknya warna pada lukisan dan bunyi pada seni musik. Karena warna cat sebelum digunakan belum memiliki arti apa-apa dan masih bersifat netral, adapun kata-kata (bahasa) sudah memiliki arti dan merupakan sebuah lambang yang telah 
disetujui masyarakat sebelum dipergunakan. Bahasa ialah sistem ketandaan yang ditentukan atau berdasar pada perjanjian (konvensi) di masyarakat. Dan siatem ketandaan tersebut disebut semiotic (Pradopo, 2010, p. 122).

Maka perlu ada kegiatan analisis puisi itu sendiri. Puisi dianalisis dengan tujuan memahami maknanya. Usaha menangkap dan memaknai teks puisi adalah dengan kegiatan menganalisis. Karya sastra ialah struktur yang bermakna. Mengingat dengan medium bahasa, sebuah sistem tanda yang memiliki makna disebut karya sastra (Pradopo, 2010, p. 122). Karena sebagai sebuah karya seni, puisi dapat dikaji dari apa yang terkandung dan menjadi unsur pembentuknya yang beragam (A Teeuw, 1980, p. 12).

Seperti karya sastra yang berupaya menjelaskan dengan apa yang terjadi antara Palestina dan Israel, yakni sebuah puisi berjudul Al-Quds yang ditulis pada tahun 1997. Seperti yang kita tahu hari ini, masih berlangsung dan tiada habisnya, menjadi perbincangan panjang dunia. Konflik ini tidak hanya menyebabkan keributan di sekitar Palestina dan Israel sendiri, namun juga di negara-negara lain. Terutama yang memiliki hubungan diplomat dengan kedua negara yang tengah berseteru. Atau di negara-negara bagian Arab yang memiliki ikatan sejarah dan hubungan emosional yang kuat dengan Palestina ataupun Israel. Dan konflik ini merupakan satu dari banyaknya rangkaian konflik di dunia Arab.

Nizar Qabbani yang merupakan pencipta puisi Al-Quds, menjadi salah satu penyair yang terkena dampaknya. Bukan hanya sebagai seorang penyair, beliau sebelumnya sempat menjabat menjadi seorang politisi, tepatnya diplomat Suriah di Mesir. Hal tersebut tidaklah berlangsung lama karena pada tahun 1944 ia berhenti menjadi seorang diplomat dan lebih memilih mencurahkan perhatiannya pada hal yang paling ia cintai yakni puisi. la seorang penyair yang berpengaruh pada abad ke-20 melalui puisi romantis dan politisnya. 
Lahir di Damaskus pada tanggal 21 Maret 1923. Puisi Nizar Qabbani terkenal dengan warna yang sensual dan romantis. Namun setelah kematian isterinya yang tewas akibat bobroknya pemerintahan di negara-negara Arab, menjadi titik balik dalam hidupnya. Akhirnya beliau lebih banyak melahirkan puisi-puisi politik yang bernada kritik dan sindiran untuk para pemimpin negara-negara Arab. la berang dengan para pemimpin negara-negara Arab, tragedi yang disebut sebagai tragedi "Ledakan Keduataan Iraq di Beirut" terjadi pada tahun 1981. Walaupun memang sebelum tragedi tersebut terjadi Nizar Qabbani sempat beberapa kali membuat puisi politik. Karya-karya bernada kritikan dan terkenal antara lain: "Kematian Orang-orang Arab", " درس "قي الرسم (Pelajaran Menggambar: 1986), "مأزا مع الإرهام" (Aku dan Terorisme), "/لقس" (Yerussalem: 1997), dan "خبز وحشيش وقمر" (Roti, Hasis, dan Rembulan: 1954).

Sebagian besar karya di atas berisi kritikan dan sindiran untuk para pemimpin negara-negara Arab, mewakili suara rakyat yang tidak tersalurkan dan tak mampu diungkapkan secara langsung, apalagi aspirasi dalam bentuk fisik. Puisi-puisi tersebut terhimpun dalam antologi puisi terjemahan karya Irfan Zakki Ibrahim berjudul "Yerussalem, Setiap Aku Menciummu: Puisi-puisi Cinta dan Politik Nizar Qabbani" terbitan Akar Indonesia tahun 2006. Dari kumpulan puisi di atas, puisi yang cukup menarik dari segi isinya untuk dikaji adalah Al-Quds, dalam bahasa Arab ditulis "قلقس" yang artinya Yerussalem ditulis pada tahun 1997.

Yerusalem, yang dalam bahasa Ibrani disebut sebagai Yerushalayim, dan dalam bahasa Arab disebut Al-Quds, kota suci tiga agama merupakan salah satu kota tua di dunia. Dikelilingi oleh benteng batu, tempat berdirinya sejumlah situs tersuci di dunia yang mewakili tiga agama samawi, yakni Islam, Kristen, dan Yahudi. Sejarah mencatat, kota ini pernah berulang kali direbut, ditaklukan, dihancurkan dan dibangun kembali oleh pihak yang berbeda. Seakan setiap lapis dindingnya merupakan ribuan lapis kertas yang mencatat sejarah masa lalu yang disaksikannya. Di dalamnya, umat Kristen 
memiliki Gereja Makam Kudus atau Church of The Holy Sepulchre yang terletak di lokasi penting yang berkaitan dengan kematian, penyaliban, dan kebangkitan Yesus. Umat Yahudi memiliki Kotel, Dinding Ratapan, atau Tembok Barat (sisa dinding penahan gunung tempat berdirinya Bait Suci zaman dulu) yang terletak di wilayah mereka dan terdapat Ruang Maha Kudus. Situs paling suci umat Yahudi. Bagi umat Islam, yang memiliki kawasan paling luas memiliki Kubah Batu (Kubah As-Shakrah atau Dome of Rock) dan Mesjid Al-Aqsa yang sering di sebut sebagai Haram Al-Sharif di dalamnya. Menjadikan kota ini di perebutkan dengan cara musyawarah hingga perang.

Hal tersebut memberi dampak yang sangat berarti bagi orang sekitar kota karena menyebabkan kerusakan yang signifikan, mencakup kerusakan ekonomi, sosial, budaya bahkan kerusakan yang tak nampak pada diri manusia seperi kerusakan psikis.

\section{LANDASAN TEORITIS DAN METODE}

Sumber data dalam penelitian ini adalah puisi karya Nizar Qabbani berjudul Al-Quds yang dimuat dalam antologi puisi terjemahan berbahasa Indonesia "Yarusalem, Setiap Aku Menciummu" oleh Irfan Zaki Ibrahim (2016) dari kumpulan puisi Nizar Qabbani. Dan untuk sumber berbahasa arab diambil dari internet situs nizariat.com merupakan sebuah surel dan bagi para pecinta karya Nizar Qabbani dengan basis page berbahasa Arab. Nizariat sendiri adalah sebutan untuk penggemar karya-karya Nizar Qabbani.

Dalam penelitian ini data diperoleh dengan teknik studi pustaka dan teknik simak dan catat. Teknik studi pustaka adalah teknik yang cara memperoleh datanya adalah dengan menggunakan sumber-sumber tertulis (Subroto, 1992, p. 42). Teknik simak dan catat dimana peneliti menyimak dan meneliti dengan akurat sumber-sumber data tertulis yang berhubungan dengan sasaran penelitian untuk kemudian dicatat (Subroto, 1992, p. 41). 
Selanjutnya adalah tahap analisis dengan menggunakan pendekatan Teori Semiotika Charles Sanders Pierce. Pada prinsipnya, peneliti ingin menganalisis tanda yang terdapat dalam puisi tersebut dengan cara menguraikannya dalam bentuk segitiga tanda atau triadic Pierce kemudian mendeskripsikannya.

Langkah akhir dalam penelitian ini ialah menentukan sebuah simpulan berdasarkan hasil penelitian terhadap puisi Al-Quds karya Nizar Qabbani yang ditulis tahun 1997 tersebut. Dengan menggunakan pendekatan teori Semiotika Charles Sanders Pierce, simpulan ini berupaya menjawab pertanyaan-pertanyaan yang terdapat dalam Rumusan Masalah Penelitian. Yakni bagaimana deskripsi Yerusalem dalam puisi Al-Quds karya Nizar Qabbani dan aplikasi teori Semiotika Charles Sanders Pierce.

\section{HASIL DAN PEMBAHASAN}

Terdapat beberapa bait puisi yang memiliki makna yang belum jelas maknanya, maka perlu masih perlu dilakukan analisis guna mendapat penafsiran yang komprehensif. Maka pada bait-bait tersebut akan dilakukan analisis dengan menggunakan teori Semiotika Charles Sanders Pierce.

Dan hampir seluruh bait memiliki kalimat yang mesti dianalisis, beberapa bait lainnya memiliki kalimat sempurna yang maknanya dapat diketahui secara langsung. Kemudian beberapa bait memiliki hubungan dengan bait lainnya, atau suatu bait merupakan terusan dari bait sebelumnya seperti pada bait 14-15 dan 16-17.

a. بَ بـ "Aku menangis hingga habsi air mataku..." menandakan bahwa dirinya telah menangis dalam waktu yang lama hingga air matanya habis, dan waktu yang lama menjadi penanda sebenar-benarnya meratap, walaupun tidak menjadi sebuah parameter, namun cukup membuktikan kesedihan yang dialami si tokoh. 'Tangis' yang dimaksud lebih merujuk pada kegiatan umat Yahudi ketika mereka berada di Tembok Ratapan 
untuk beribadah, tepatnya berdoa, mereka melakukannya dengan cara meratap sambil menangis dan mencurahkan seluruh isi hati di tembok ratapan. Jadi tokoh aku disini mewakili orang Yahudi ketika mereka berdoa sambil bersedih.

Orang Yahudi percaya bahwa dinding yang menjadi saksi kejayaan nabi Sulaiman AS tersebut sebagai bagian dari sebuah kuil Yahudi yang telah berdiri selama ratusan tahun, sebuah bangunan yang disebut sebagai Bait Suci Kedua. Orang Yahudi percaya bahwa di tembok tersebut berdiam "Shekinah" (kehadiran ilahi). Artinya berdoa di sana sama dengan berdoa pada Tuhan, sehingga tatkala mereka sedang berdoa disana, mereka meratap. (Wikipedia Indonesia) Hampir sama dengan istilah sakinah dalam islam, yang berarti memberi ketengan kepada hati, artinya terdapat kehadiran ilahi.

Istilah shekinah sendiri tidaklah muncul dalam injil, namun diciptakan oleh para rabi Yahudi yang secara harfiah bermakna "yang menyebabkan hadir" menjelaskan bahwa kehadiran ilahi telah datang, dengan kata lain tempat berdiamnya Tuhan Allah di bumi. (Biblical Answer).

Seperti yang banyak kita jumpai di berbagai literatur Yahudi atau kita dapat menjumpainya di internet, dengan menggunakan Tefilin (artibut kepala hingga lengan atas yang sering digunakan ketika beribadah pagi di sinagog atau ketika berdoa di tembok ratapan) mereka mengepalkan tangan dan menangis layaknya sedang memohon kepada sang pencipta.

Sehingga tangis disini lebih menjadi gamabaran atau wakil dari umat Yahudi. 
INDEKS: Orang Yahudi percaya bahwa di tembok tersebut berdiam "Shekinah" (kehadiran ilahi). Artinya berdoa di sana sama dengan berdoa pada Tuhan, sehingga tatkala mereka sedang berdoa disana, mereka meratap. (Wikipedia Indonesia)

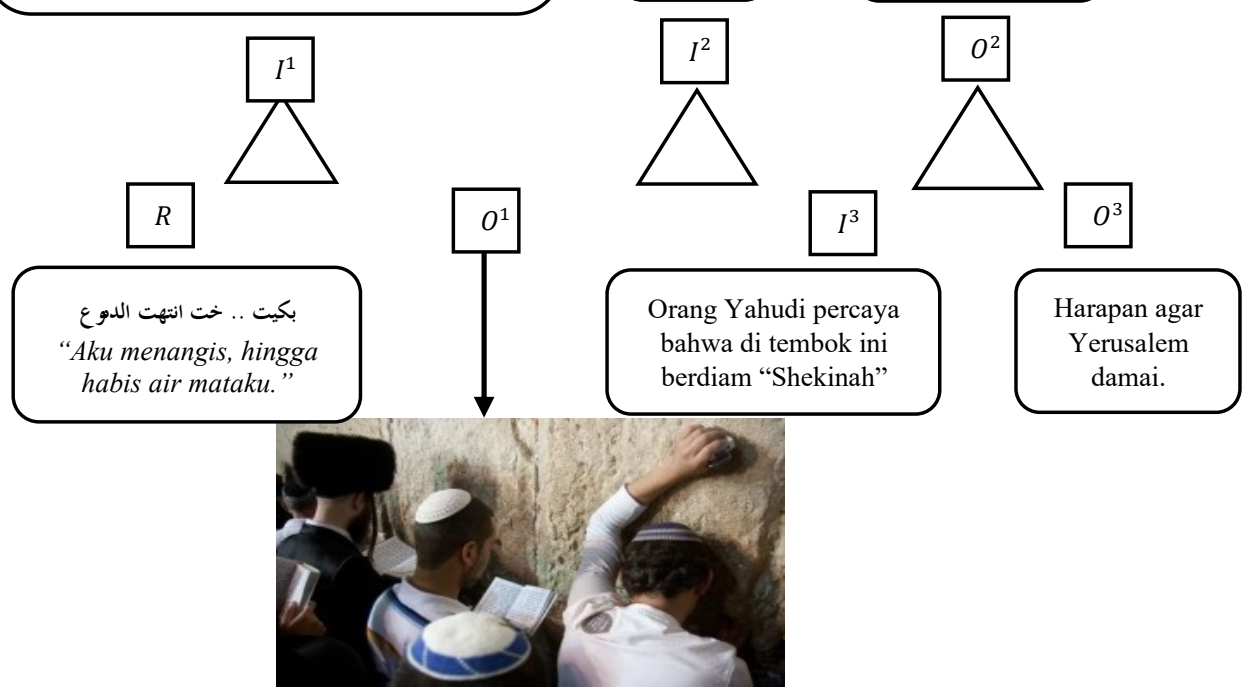

Gambar 1 Umat Yahudi sedang berdoa di Dinding Ratapan

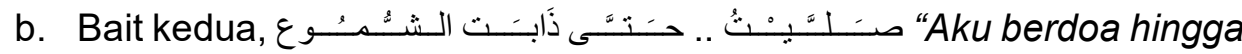
lilin meleleh..." menjelaskan bahwa tokoh aku berdoa hingga lilin meleleh, layaknya bait yang pertama artinya ia berdoa dalam waktu yang lama, namun disini mewakili sesuatu yang berbeda. Dan waktu yang lama menjadi penanda sebenar-benarnya berdoa. Berdoa disini dilakukan dengan memakai sebuah lilin, yang mana lilin menjadi simbol orang Kristen karena menjadi simbol Yesus yang membawa terang pada kahidupan.

"Terang itu bercahaya di dalam kegelapan dan kegelapan itu tidak menguasainya." (Yohanes 1: 5).

Di Eropa, omset penjualan lilin mencapai $45 \%$ menjelang Natal. Memang dalam Alkitab tidak ada satu ayat pun yang mengaitkan lilin dengan natal, budaya ini ada saat perayaan pesta Saturnalia sejak jaman Romawi (Rachman, 2011, p. 132). 
Maka tokoh aku disini mewakili orang cara berdoa umat Kristen akan kesedihan mereka.

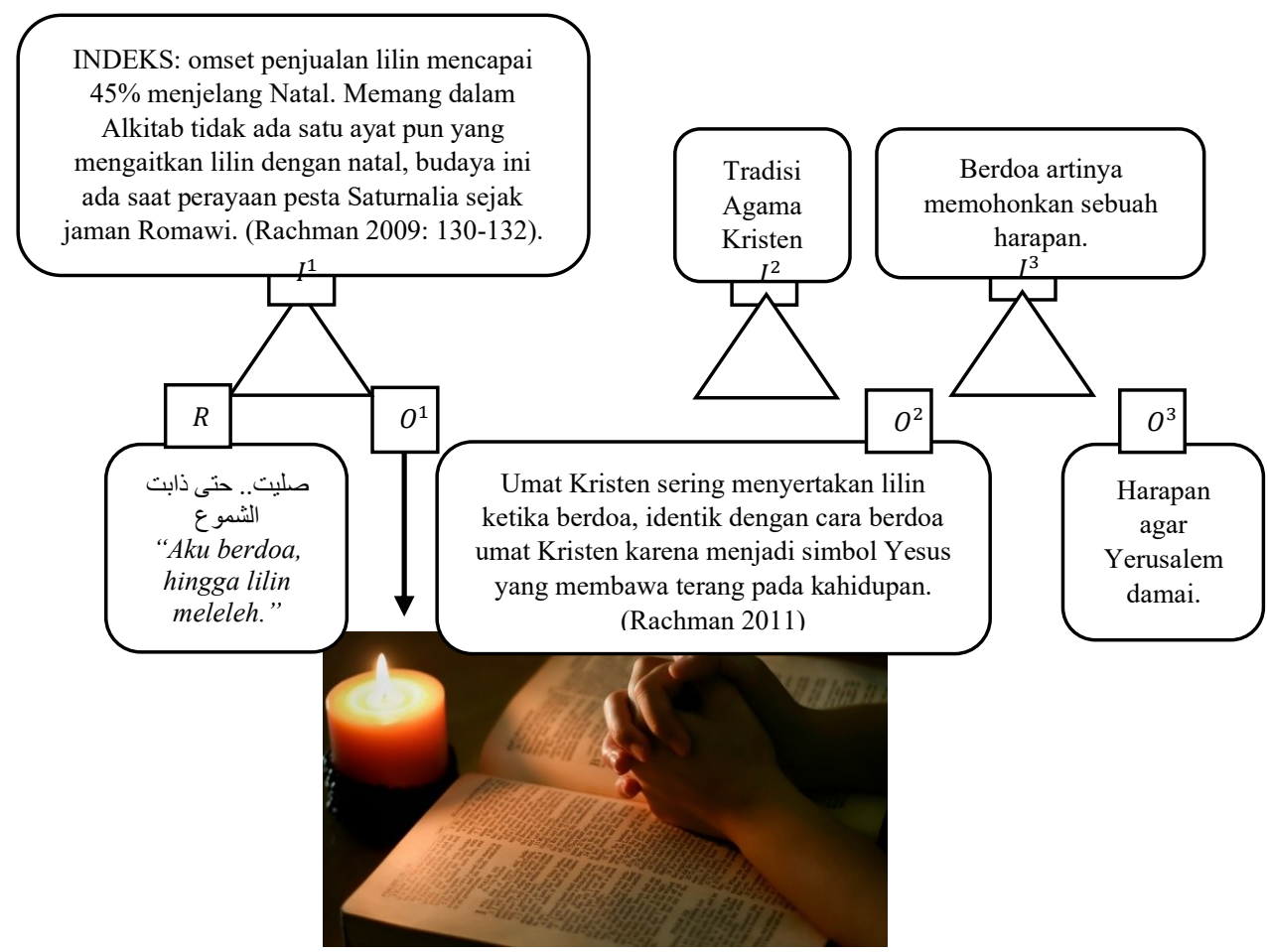

Gambar 2 Lilin menjadi simbol Umat Kristen.

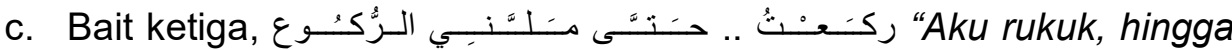
lantai bosan denganku..." menunjukan bahwa tokoh aku sedang melakukan ruku. Yang mana rukuk sendiri merupakan rukun penting dalam shalat bahkan dianjurkan untuk berlama-lama dalam rukuk dan juga sujud. Banyak orang yang berbondong-bondong menyempurnakannya, karena dipercaya memili manfaat baik secara agama maupun kesehatan. (Nusantarakini.com) Sebagaimana firman Allah SWT dalam Al-Quran :

$$
\text { يأيها الذين آمنوا اركعو ا واسجدو ا واعبدوا ربكم و افعلوا الخير لعلكم تقلحون. }
$$

“Hai orang-orang beriman, ruku'lah kamu, sujudlah kamu, sembahlah Tuhanmu dan perbuatlah kebajikan, supaya kamu mendapat kemenangan." (QS. Al-Hajj: 77).

Dan si tokoh aku melakukannya dalam tempo yang cukup lama, layaknya bait-bait sebelumnya, yakni bait pertama dan kedua. Hal ini menjadi bukti bahwa waktu yang lama, menjadi penanda sebenar-benarnya ruku, 
artinya tokoh aku telah melakukan sebenar-benar sholat (khusyuk). Bisa dalam bentuk rukuk yang lama atau melakukan sholat dalam jumlah rakaat yang banyak.

Hal ini menyebabkan kata 'ruku' sendiri menjadi bosan padanya. Karena ia terlalu sering melakukannya. Dan ruku disini menjadi simbol umat Muslim, karena hanya umat muslim yang melaksanakan shalat dan menjadikan rukuk sebagai salah satu rukunnya sebagai rangkaian ibadah umat muslim dan bahkan lebih dalam dari itu, yakni menjadi tiang dari agama.

Dan ruku dalam tempo yang lama juga dapat menjadi penanda akan hadirnya kekhusyukan dalam seseorang yang sedang beibadah, dan ketika khusyu berarti ada sesuatu yang benar-benar diinginkan atau dapat menjadi ekspresi sebuah kesedihan. Disini dapat ditafsirkan bahwa kesedihan yang dialami diakibatkan oleh Yerusalem yang masih dibalut oleh perang.

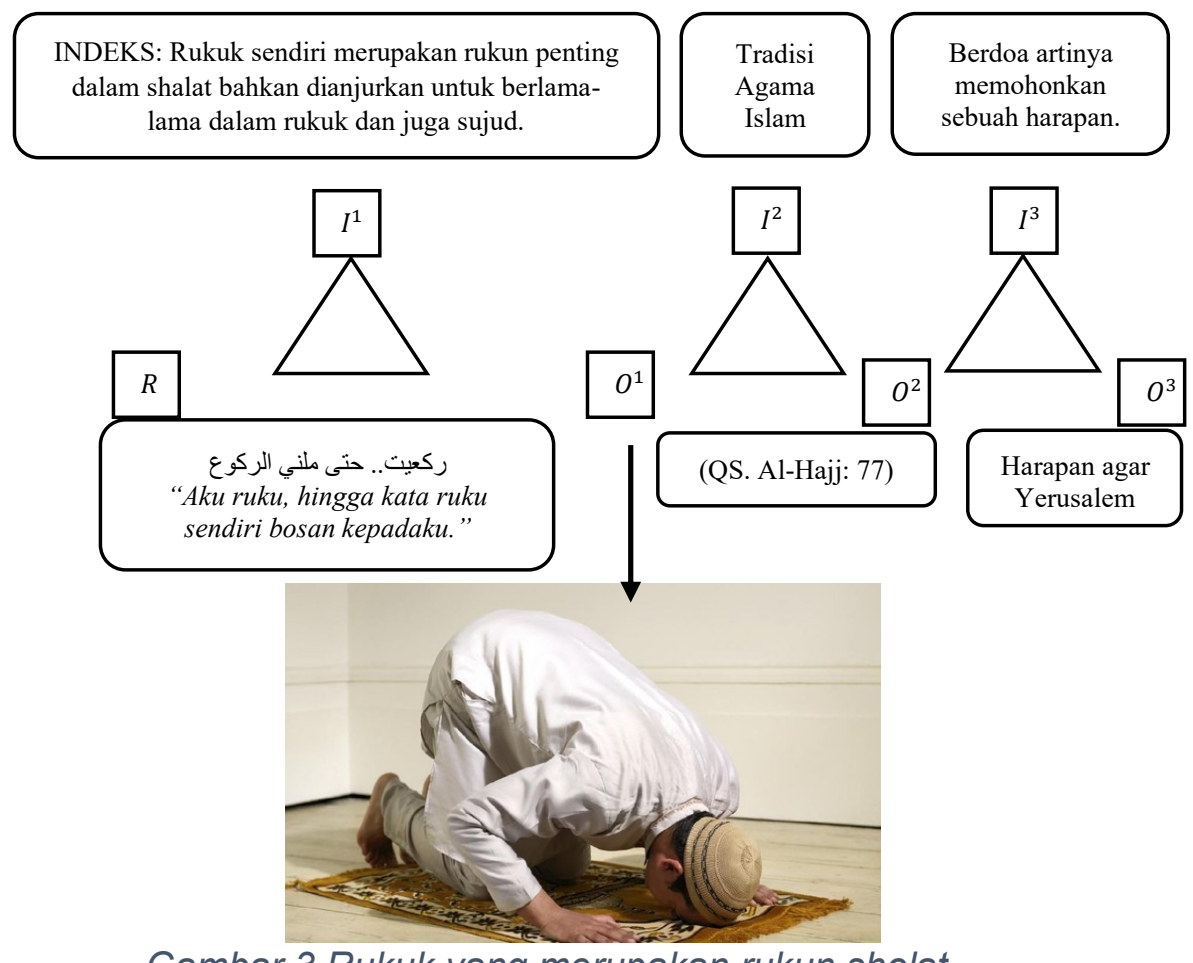

Gambar 3 Rukuk yang merupakan rukun sholat 


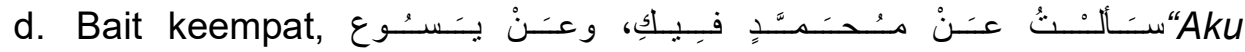
bertanya padamu tentang Muhammad dan Yesus..." menunjukan bahwa tokoh aku sedang bertanya kepada kota suci Al-Quds tentang Muhammad dan Yesus. Yang mana Muhammad sendiri adalah simbol untuk umat Islam dan Yesus sebagai simbol orang Kristen. Namun tiba-tiba pertanyaan hanya berhenti pada kalimat ini di bait ketiga. Hal ini menunjukan bahwa penulis membuat sebuah kalimat pertanyaan retoratif, yakni sebuah pertanyaan yang tidak perlu mendapatkan sebuah jawaban.

Tidak adanya jawaban bisa disebabkan oleh beberapa faktor misalnya karena jawaban telah diketahui oleh khalayak umum atau yang diberi pertanyaan bukanlah komponen yang mampu menjawab. Disini sesuatu yang ditanya adalah 'Al-Quds' yang merupakan sebuah kota atau benda mati, maka karena faktor kedua lah mengapa penulis membuat pertanyaan retoratif. Hal ini menyedihkan, mengingat Al-Quds tidak dapat memberikan jawaban. Karena sesuai dengan genre puisinya yang merupakan sebuah ratapan atau ekspresi kesedihan.

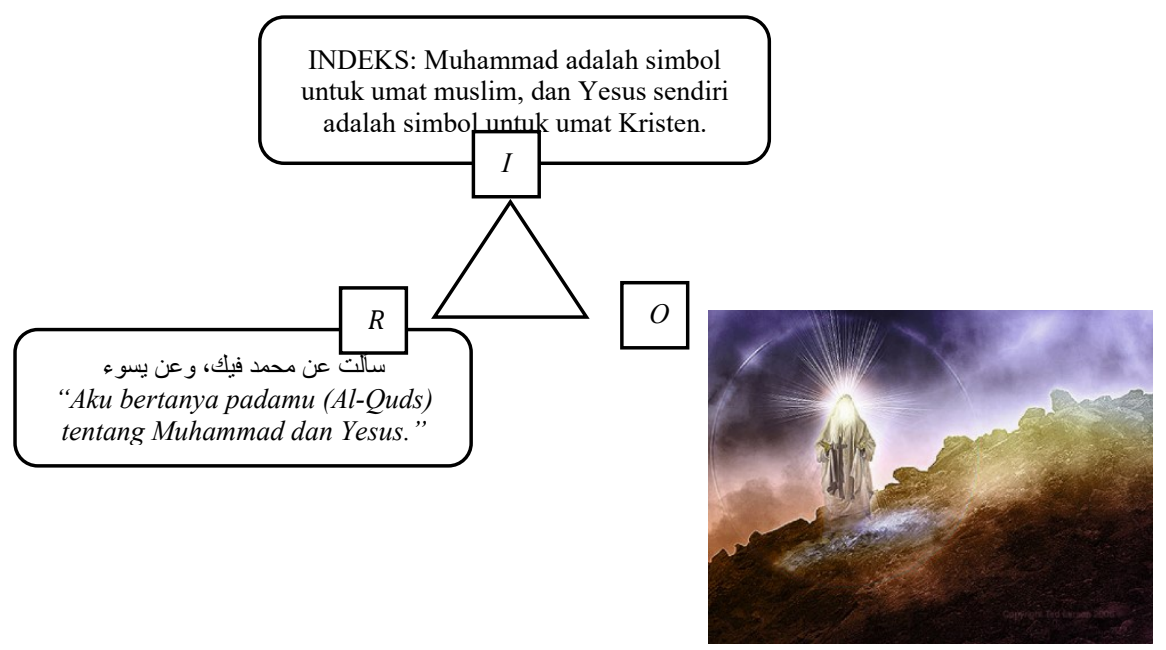

Gambar 4 llustrasi Muhammad SAW.

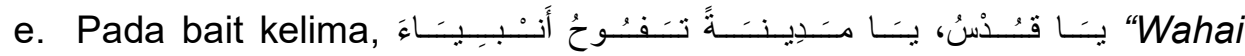
Quds, tanah yang dicium para nabi..." menunjukan bahwa Yerusalem atau Al-Quds adalah sebuah kota yang telah di cium oleh para nabi. 'Di cium' disini bisa berarti ‘telah dihirup' udaranya, bisa juga diartikan sebagai telah 'dilewati' atau 'dijelajahi' oleh para nabi. Dimulai dari nabi Ibrahim AS yang menjadi bapa dari ketiga agama yakni Islam, Kristen, dan Yahudi menjadi agama yang memiliki keterkaitan dengan 
sosok Ibrahim, dan ketiga agama tersebut kerap disebut sebagai agama Abrahamik.

Mengingat bahwa para nabi sendiri banyak yang berasal dari kalangan Bani Israil yang notab nabi Ibrahim AS beserta sang istri Sarah berdakwah dari Babilonia sebelum akhirnya hijrah ke Mesir. Pada masa ini juga lahir Luth AS, anak dari Haran saudara nabi Ibrahim AS. Kemudian Nabi Ismail putra Ibrahim dari Hajar dan Ishak putra Ibrahim dari Sarah. Ishak menikahi Rifqi binti Batwail melahirkan anak kembar bernama Aishu (Esau) dan Yakub AS. Kemudian dari Yakub lahir 12 orang anak termasuk Nabi Yusuf AS.

Dari keturunan nabi Yakub AS tersebut, seorang anak bernama Yehuda menjadi kakek moyang dari nabi Sulaiman AS. Dan anak lainnya bernama Lewi yang dalam keturunannya terdapat nabi Musa AS, nabi Harun AS, nama llyas AS, nabi Zakaria AS dan nabi Yahya AS. Sebagian berpendapat juga bahwa siti Maryam keturunan Lewi pendapat lainnya menyatakan ia keturunan Yehuda.

Dilanjutkan oleh nabi Zakaria AS yang akhirnya memiliki anak yang juga seorang nabi yakni nabi Yahya AS, dan keponakannya siti Maryam yang melahirkan seorang nabi bernama Isa yang nantinya akan menjadi nabi besar umat Kristen.

Kemudian seorang raja yang mashur kedudukannya karena selain memimpin manusia ia pun dianugerahi Allah untuk memimpin jin dan hewan. Menjadi raja dari segala makhluk, yakni Nabi Sulaiman AS, yang istananya di klaim berada di bawah bangunan Masjidil Aqsa. Dan nabi Sulaiman AS sendiri merupakan anak dari nabi Daud AS yang menjadi raja sebelumnya.

Seperti yang kita tahu dalam peristiwa Isra Miraj, Rasulullah SAW sebelum melakukan perjalanan ke sidratul muntaha ia sempat melewati Masjid Al-Aqsa terlebih dahulu. Yerusalem adalah tempat inspirasi bagi banyak nabi. (Sejarah Dunia Kuno) 

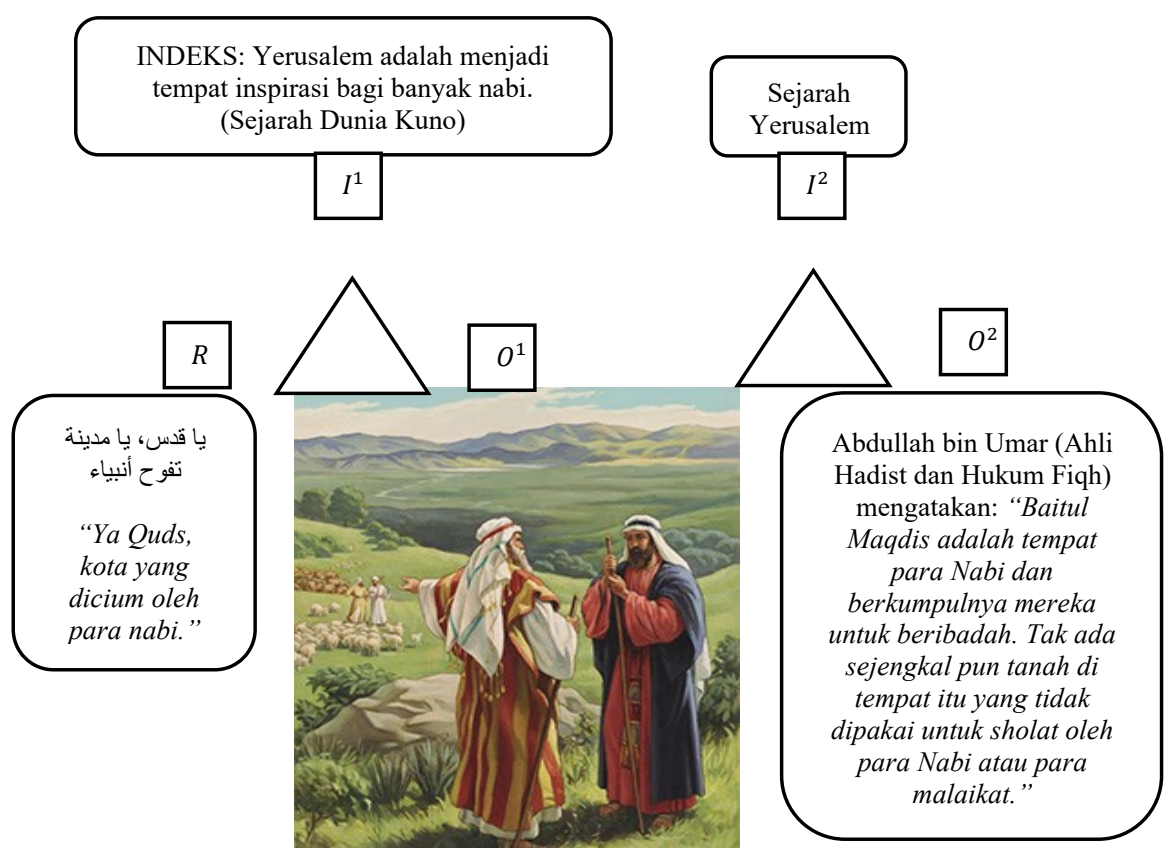

Gambar 5 Ilustrasi para nabi yang pernah safar di Yerusalem.

\section{PENUTUP}

Puisi “Al-Quds” karya Nizar Qabbani yang ditulis pada tahun 1997 merupakan satu dari banyak karya buahnya yang bernada kesedihan. Tidak hanya itu, puisi ini pun sebagai bentuk protes pada keadaan politik pemerintah negara-negara Arab saat itu. Berawal dari kematian kakak perempuannya sebagai korban dari tradisi patriarki di timur, kemudian kematian istri tercintanya akibat sebuah insiden di gedung kedutaan yang bertepatan di Beirut.

Dua pengalaman tersebut cukup untuk menarik Nizar Qabbani dalam dunia politik disamping ia memang berlatar belakang pendidikan sosial hukum dan berprofesi sebagai seorang diplomat. Namun Nizar Qabbani yang kita kenal hari ini ialah seorang sastrawan ulung yang boleh disebut sebagai 
penyair yang cukup produktif dalam masa hidupnya. Disamping itu warna puisi kesedihan, cinta, serta sensual menjadi ciri khas dari karyanya. Ketiga warna itulah yang senantiasa kita kenal dari seorang Nizar Qabbani, seorang penyair dibanding seorang diplomat.

Deskripsi Yerusalem dalam puisi Al-Quds merupakan ungkapan kesedihan sang pengarang yang melihat kenyataan di dalam Al-Quds atau Yerusalem, kota damai yang mana didalamnya berdiri tiga agama secara berdampingan. Namun mesti ganggu oleh kepentingan luar yang mampu menghancurkan perdamaian yang ada di dalamnya. Perang Israel-Palestina seakan menghancurkan rona indah yang ada didalamnya, dan menghapus senyum serta tawa anak-anak yang harusnya banyak terdengar disana.

Banyak kerugian yang dialami dari sisi ekonomi, budaya, terutama politik dan sosial dari konflik tersebut. Seperti yang kita tahu bahwa umat beragama yang tinggal di Yerusalem dapat hidup berdampingan, namun konflik Israel-Palestina ini telah merubah banyak hal. Dari segi ekonomi, Palestina hingga saat ini tidak memiliki kondisi ekonomi yang stabil, terutama di jalur Gaza sebagai tempat yang paling sering diserang oleh Israel sering mengalami krisis ekonomi. Hal ini karena kurangnya minat beli yang disebabkan oleh blokade yang dilakukan terhadap Gaza. Namun hal tersebut tidak mengurangi antusiasme dalam menyambut bulan suci ramadhan. (Suara Palestina News Agency)

Dalam bidang budaya terutama budaya kemasyarakatan tidak mengalami perubahan signifikan karena Israel maupun Palestina memiliki budaya yang tidak jauh berbeda. Dalam bidang politik Israel maupun Palestina memiliki kekuatan yang yang sama-sama kuat. Namun dalam segi dukungan memiliki kekuatan yang jauh berbeda, mengingat Israel memiliki dukungan dari negara adi daya Amerika Serikat. Inilah mengapa negaranegara islam di seluruh dunia harus bersatu. 
Dalam bidang sosial yang mengalami kondisi merugikan ialah Palestina. Blokade yang dilakukan dimana-mana membuat Palestina cenderung tertutup karena sulitnya akses dan memiliki kualita hidup yang kurang baik. Massyarakat Palestina setiap harinya selalu mengalami kekhawatiran, karena serang dari Israel selalu terjadi secara tiba-tiba, tak mengenal waktu dan tempat. Kini hanya ada tangis dan air mata, bahkan $\mathrm{Aa}$ Gym dalam ceramahnya di Kajian MQ Pagi tanggal 24 Juni 2018 :

"Ada istilah di bulan suci ramadhan orang Palestina sahur di dunia dan berbuka di akhirat."

Bukti bahwa kehidupan bagi masyarakat Palestina tidak panjang, selalu berada di ambang kematian.

Dalam puisi Al-Quds nampak beberapa simbol yang muncul dan menjadi identitas Yerusalem, seperti "tanah yang dilewati oleh para nabi", "menara dari menara", "jalan terpendek dari dunia ke akhirat" hal yang sangat lekat dengan Yerusalem. Bukan hanya tergambar dalam puisi AlQuds namun di hati banyak orang, terutama orang sekitar dan mereka yang terikat secara emosional dengan sejarah.

Teori semiotika Charles Sanders Pierce merupakan teori yang tepat dalam pemilihan pisau analisis, terutama digunakan untuk mengupas makna yang terkandung dibalik puisi berjudul "Al-Quds" karya Nizar Qabbani ini. Mengingat puisi tersebut tidaklah dapat bisa di lepaskan dari sejarah yang menyelimutinya. Karena perang Israel-Palestina sendiri telah berlangsung sejak zaman kekhalifahan. Maka perlu sumber virtual dan interpretasi dari tiap baitnya, guna mencapai pemahaman yang baik dalam proses pencarian makna puisi tersebut melalui elemen Representament, Objek, dan Interpretannya. Selain itu puisi ini pun menyadarkan akan pentingnya perdamaian bagi seluruh umat manusia, bagi banyak orang, terutama untuk anak-anak sebagai penerus bangsa dan investasi paling penting tiap negara. 
Hijai - Journal on Arabic Language and Literature | ISSN: 2621-1343

\section{DAFTAR PUSTAKA}

A Teeuw. (1980). Sastra Baru Indonesia. Flores: Nusa Indah.

Pradopo, R. D. (2010). Pengkajian Puisi: Analisis Strata Norma dan Analisis Struktual dan Semiotik. Yogyakarta: Gajah Mada University Press.

Rachman, R. (2011). Hari Raya Liturgi Sejarah dan Pesan Pastoral Gereja. Jakarta: BPK Gunung Mulia.

Sobur, A. (2006). Semiotika Komuniasi . Bandung: Remaja Rosdakarya.

Subroto. (1992). Penelitian Kualitatif. Jakarta: Raja Grafindo Persada. 